\title{
Cost of illness of atopic asthma and seasonal allergic rhinitis in Germany: 1 -yr retrospective study
}

\author{
B. Schramm*, B. Ehlken*, A. Smala*, K. Quednau\#, K. Berger*, D. Nowak
}

\begin{abstract}
Cost of illness of atopic asthma and seasonal allergic rhinitis in Germany: 1-yr retrospective study. B. Schramm, B. Ehlken, A. Smala, K. Quednau, K. Berger, D. Nowak. (C) ERS Journals Ltd 2003.

ABSTRACT: The purpose of this study was to evaluate the cost of illness of moderateto-severe atopic asthma and/or seasonal allergic rhinitis (SAR) in Germany from the perspective of third-party payers (TPP) and patients.

Five-hundred patients ( 276 children/adolescents) with moderate-to-severe asthma and/ or SAR were included in this cross-sectional study. Information was collected using a specific patient questionnaire and the abstraction of patient records.

Overall, annual costs per patient increased with the severity of atopic asthma and if it was associated with SAR. The average annual cost of $S A R$ was $€ 1,089$ per child/ adolescent and $€ 1,543$ per adult. Annual costs of severe asthma plus SAR increased to $€ 7,928$ per child/adolescent and to $€ 9,287$ per adult. For TPPs, the main cost drivers were medication, hospitalisation, and rehabilitation. The most significant costs for patients were household modifications. For children/adolescents, $60-78 \%$ of the expenditures were direct costs, while in adults, $58 \%$ of expenditures were indirect costs. It was also observed that patients with moderate and severe asthma used inhaled corticosteroids less frequently than recommended by treatment guidelines.

In summary, the total cost for patients increases with the severity of atopic asthma and/or seasonal allergic rhinitis and indirect costs represent a large proportion of the total cost.

Eur Respir J 2003; 21: 116-122.
\end{abstract}

*MERG Medical Economics Research Group, Munich, "Health Economics, Novartis Pharma, Nuremberg and Institute and Outpatient Clinic for Occupational and Environmental Medicine, Ludwig-Maximilians-University, Munich, Germany.

Correspondence: B. Schramm, Medical Economics Research Group, PaulGerhardt-Allee 42, D-81245 München, Germany.

Fax: 498945791234

E-mail: Barbara.Schramm@mergmunich.de

\author{
Keywords: Atopic asthma \\ cost of illness \\ direct costs \\ indirect costs \\ rhinitis \\ severity of disease
}

Received: March 82002

Accepted after revision: August 192002
International studies have shown an increase in the prevalence of allergic diseases [1, 2]. Nasal allergies, including seasonal allergic rhinitis (SAR), afflict 13.4\% of adults (20-44 yrs) in East Germany (Erfurt) and $23 \%$ in West Germany (Hamburg) [3]. In comparison, $2.1 \%$ of adults in the East and $4.4 \%$ in the West have bronchial asthma. Particularly significant, however, is the high prevalence of bronchial asthma in children. The International Study of Asthma and Allergies in Childhood observed that $14 \%$ of German children aged 13-14 yrs had self-reported asthma [4]. More than $70 \%$ of asthma patients report nasal symptoms [5] and $20 \%$ of SAR patients develop bronchial asthma later in life [6]. Thus, SAR and bronchial asthma rank among the most common chronic and allergic diseases. Most allergic persons are sensitised to more than one common allergen. Thus, symptoms may present episodically or persistently.

From the societal perspective, the economic impact of asthma in Germany was $€ 2.62$ billion in 1992 [7] and $€ 2.97$ billion in 1996 [8], of which $61.4 \%$ were direct costs [7]. Analysis of 1992 data shows a positive correlation between illness severity and total cost. Total annual cost per patient ranges from $€ 184$ for mild asthma to $€ 7,567$ for severe asthma [9]. The most recent empirical data, for 1995-1996, clearly show increased costs depending upon illness severity [10]. These are the first published data that reveal the total cost of atopic asthma/SAR in Germany and the personal expenses of patients.

Clinical studies demonstrate that intranasal steroids, antihistamines and decongestants relieve nasal symptoms in SAR patients. Furthermore, treatment reduces the severity of asthma symptoms and increases peak flow rates $[11,12]$. Innovative therapies are often expensive and therefore must be effective, efficient and improve quality of life. Prospective analytical studies are therefore justified. The objective of this study was to describe the burden due to SAR and atopic asthma for children/adolescents and adults in Germany.

\section{Methods}

\section{Research design}

This was a retrospective cross-sectional study. All direct medical and nonmedical costs were evaluated from the perspective of third-party payers (TPPs) and patients. Indirect costs were also evaluated.

\section{Recruitment}

Five areas (urban and rural), evenly distributed across Germany, were selected to account for the 
effect of sociodemographical status on the prevalence of atopic diseases [13]. Urban areas were cities with $>400,000$ inhabitants and rural areas were towns with $<50,000$ inhabitants. Pulmonologists and paediatricians $(n=205)$ were randomly selected from the local telephone register. Subjects were recruited by 36 doctors, who were each asked to enrol up to 25 patients fulfilling the inclusion criteria. Patients who agreed to complete a patient questionnaire received the questionnaire by mail and returned it directly to the Medical Economics Research Group, Munich, Germany. If patients gave their informed consent, data was obtained from their records.

\section{Criteria for inclusion and exclusion}

Patients (aged 6-70 yrs) with moderate-(asthma 3) to-severe (asthma 4) atopic asthma and/or SAR were included. Classification of asthma severity was based on Global Initiative for Asthma (GINA) recommendations [14]. Patients were only included during the study period (March 1, 1999 to February 29, 2000) if treatment was initiated prior to March 1, 1999. Patients with a hypersensitivity to analgesic drugs indistinguishable from atopic asthma were excluded. Written informed consent was obtained from patients.

\section{Data collection}

The following data were collected using a specific patient questionnaire: demographical characteristics, consultations with doctors (family physicians and specialists), hospitalisations (including emergencies), rehabilitation care, sickness benefits, ad hoc expenses (e.g. over-the-counter (OTC) medication), co-payments (inpatient care and physiotherapy), household modifications (e.g. renovations, replacement of carpets with washable floors, purchase of beddings for patients sensitised against house dust mites), auxiliary devices and nonrefundable therapies. Questions regarding day care for asthmatic children, absence from work and disability were also answered. Patients were interviewed directly regarding absence from work for less than 3 days, since this requires no doctor's note in Germany. Information regarding total workdays missed due to incapacity longer than 3 days, usage of outpatient resources, prescribed medication and medication co-payments was documented by trained medical staff from patients' records into an access database. The appropriateness of this database has been tested by pilot documentation.

\section{Costing}

The burden of asthma and SAR care is due to direct medical costs (e.g. health services used for treatment) and direct nonmedical costs (e.g. caregiver costs and household modifications). Indirect costs from disability, early retirement and loss of work by patients and caregivers were also of interest.

To evaluate costs from the perspective of TPPs, the average frequency of a diagnostic or treatment service was used and multiplied by the charge. Charges for outpatient services are based on points published in the German tariff list [15], multiplied by the average value per point for medical services: pulmonologists $€ 0.03$; paediatricians $€ 0.04$.

The prescribed medications were documented from patients' records and multiplied by the reimbursable prices recorded in the German pharmaceutical index [16]. These figures were then reduced by the subtraction of patients' co-payments and statutory health insurance.

Inpatient costs were calculated using an average of the daily rate reimbursed by German TPPs for accommodation (year 2000: $€ 70.94$ ), medical services $(€ 157.61-240.28)$ [17], and rehabilitative therapies $(€ 121.50)$. Emergency transport by car cost $€ 370.94$ and $€ 46.22$ per minute by helicopter. The human capital approach was applied to calculate indirect costs arising from lost productivity [18]. The monetary value of productivity for employees was calculated from the data on gross income and number of employees [19] in the Statistical Yearbook of 1999 and was $€ 89.48$ per day. To calculate productivity losses arising from reduced working time or early retirement, the mean time loss of all patients was multiplied by $€ 89.48$ and by 220 annual working days. The productivity lost if asthma or SAR led to early retirement was calculated in a similar manner (€89.48 multiplied by 220 annual working days). Costs for asthma and SAR-related loss of work were calculated exclusively for patients and parents/caregivers employed during the observation period. Lost productivity due to school absences was disregarded.

Patients retrospectively estimated their own expenses for OTC medication, home modifications, auxiliary devices and nonrefundable therapies over a 12-month period. The co-payments for medication ranged from $€ 4.00-5.00$ and co-payments for inpatient accommodation were $€ 9.00$ per day.

\section{Statistics}

Patients were stratified by age (children and adolescents aged 6-17 yrs and adults aged 18-70 yrs) and illness severity.

\section{Results}

\section{Doctor and patient sample}

A total of 20 pulmonologists and 16 paediatricians recruited 885 patients. Written informed consent and a completed questionnaire were obtained from 500 patients.

\section{Patient characteristics}

Table 1 shows demographical data for the 500 patients (53\% male, $47 \%$ female), of which $55 \%$ (276) were between $6-17$ yrs (64\% males). Only $39 \%$ of the adults 
Table 1.-Demographical characteristics

\begin{tabular}{|c|c|c|}
\hline & $\begin{array}{l}\text { Children/ } \\
\text { adolescents }\end{array}$ & Adults \\
\hline Subjects $n$ & 276 & 224 \\
\hline Sex M & $64 \%$ & $39 \%$ \\
\hline Age yrs & $12 \pm 3$ & $43 \pm 14$ \\
\hline Age range yrs & $6-17$ & $18-70$ \\
\hline \multicolumn{3}{|c|}{ Disease diagnosed since } \\
\hline SAR yrs & $6 \pm 2$ & $14 \pm 9$ \\
\hline Asthma yrs & $7 \pm 3$ & $18 \pm 13$ \\
\hline $\begin{array}{l}\text { SAR and } \\
\text { asthma yrs }\end{array}$ & $\begin{array}{c}\text { SAR for } 8 \pm 3 \\
\text { Asthma for } 7 \pm 3\end{array}$ & $\begin{array}{l}\text { SAR for } 23 \pm 13 \\
\text { Asthma for } 15 \pm 11\end{array}$ \\
\hline
\end{tabular}

Data are shown as mean \pm SD unless otherwise stated. M: male; SAR: seasonal allergic rhinitis. ${ }^{\#}$ : 6-17 yrs; ๆ: $18-70$ yrs.

Table 2. - Level of illness severity

\begin{tabular}{lccc}
\hline & All patients & $\begin{array}{c}\text { Children/ } \\
\text { adolescents }\end{array}$ & Adults \\
\hline SAR & $161(32)$ & $98(36)$ & $63(28)$ \\
Asthma 3 & $107(21)$ & $71(26)$ & $36(16)$ \\
Asthma 3+SAR & $147(29)$ & $65(23)$ & $82(37)$ \\
Asthma 4 & $41(8)$ & $20(7)$ & $21(9)$ \\
Asthma 4+SAR & $44(9)$ & $22(8)$ & $22(10)$ \\
Total & $500(100)$ & $276(100)$ & $224(100)$ \\
\hline
\end{tabular}

Data are presented as $\mathrm{n}(\%)$. SAR: seasonal allergic rhinitis; Asthma 3: moderate asthma; Asthma 4: severe asthma.

(18-70 yrs) were male. Children/adolescents had suffered from their illness an average of 6-8 yrs and adults 14-23 yrs. Patients with both SAR and asthma generally developed SAR first.

Table 2 shows stratification according to age, illness and illness severity. Patients originated equally from rural areas $(47 \%)$ and urban areas $(53 \%)$ as well as from Eastern $(45 \%)$ and Western Germany $(55 \%)$. Employment status was declared by $86 \%$ (370 of 430) of patients and caregivers. Of 430 respondents, 28 had to change their job due to illness: 11 became part-time, 10 retrained, and seven resigned due to their own or their child's asthma/SAR. Thirteen respondents of 430
$(3 \%)$ retired early. The mean number of days lost due to reduced productivity was 2.6 days per year.

\section{Resource utilisation}

Table 3 shows resource utilisation, such as consultations and medical services. On average, children and adolescents visited their pulmonologist or paediatrician 11 times per year and adults nine times. Other doctors were consulted by $32.5 \%(n=67)$ of children/ adolescents and $47.3 \%$ ( $\mathrm{n}=95$ ) of adults. Children/ adolescents with moderate asthma required medical services an average of 15.7 times per year and adults 11.4 times. This rose to an average of 22.0 and 21.3 times per year, respectively, as illness severity increased. If children and adolescents had only asthma, they consulted paediatricians/pulmonologists more often and required more medical services than patients with asthma and SAR.

The proportion of children/adolescents and adults with SAR receiving immunotherapy was 35\% (15 of 43 ) and $65 \%$ (20 of 31), respectively. A few hospitalisations occurred during the study. Overall, 4\% $(n=18)$ were treated as inpatients (for an average of 12.1 days (SD 11.6), 6\% were treated as outpatients, and $6 \%$ required emergency transport. Inpatient treatment (seven of 116 children) and emergency transport (12 of 125) were mainly required by children of $6-11$ yrs. Rehabilitation was prescribed for $7 \%$ of all patients.

\section{Pharmacotherapy use}

Prescribed medication was received by $37 \%$ of children and adolescents with SAR but by $94 \%$ with severe asthma and SAR. Nearly all adults received prescribed medications. Figures 1 and 2 show prescribed medication use. The most common agents used by asthma patients were inhaled sympathomimetics (including short- and long-acting sympathomimetics), followed by inhaled corticosteroids (ICS). SAR patients were mainly treated with oral antihistamines. Patients suffering from both illnesses often received intranasal agents (e.g.

Table 3. - Medical resource utilisation per patient per year (children/adolescents and adults)

\begin{tabular}{|c|c|c|c|c|c|c|c|}
\hline \multirow[t]{2}{*}{ Resource } & \multirow{2}{*}{$\begin{array}{l}\text { Percentage } \\
\text { (n) }\end{array}$} & \multicolumn{6}{|c|}{ Frequency per patient } \\
\hline & & Total & SAR & Asthma 3 & $\begin{array}{l}\text { Asthma } \\
\text { 3+SAR }\end{array}$ & Asthma 4 & $\begin{array}{l}\text { Asthma } \\
\text { 4+SAR }\end{array}$ \\
\hline \multicolumn{8}{|l|}{ Children and adolescents } \\
\hline Consultations with paediatrician/pulmonologist & $100.0(160)$ & 10.6 & 8.9 & 11.5 & 10.5 & 13.9 & 9.9 \\
\hline Consultations with others & $32.5(67)$ & 2.2 & 2.7 & 1.6 & 1.6 & 1.6 & 4.6 \\
\hline Medical services (outpatient) ${ }^{\#}$ & $94.4(151)$ & 13.8 & 10.3 & 15.7 & 11.2 & 22.0 & 17.1 \\
\hline \multicolumn{8}{|l|}{ Adults } \\
\hline Consultations with paediatrician/pulmonologist & $100.0(145)$ & 8.9 & 11.7 & 7.5 & 7.6 & 10.1 & 8.2 \\
\hline Consultations with others & $47.3(95)$ & 3.8 & 3.4 & 3.7 & 2.7 & 5.4 & 8.7 \\
\hline Medical services (outpatient) & 95.9 (139) & 16.6 & 19.5 & 11.4 & 14.6 & 21.3 & 18.9 \\
\hline
\end{tabular}

SAR: seasonal allergic rhinitis; Asthma 3: moderate asthma; Asthma 4: severe asthma. *: calculations according to patient chart; ": calculations according to patient questionnaire, medical services (outpatient), including all diagnostic procedures (e.g. allergen testing), and therapeutic treatments (e.g. hyposensitisation) in the office. Pharmacotherapy is shown separately. 


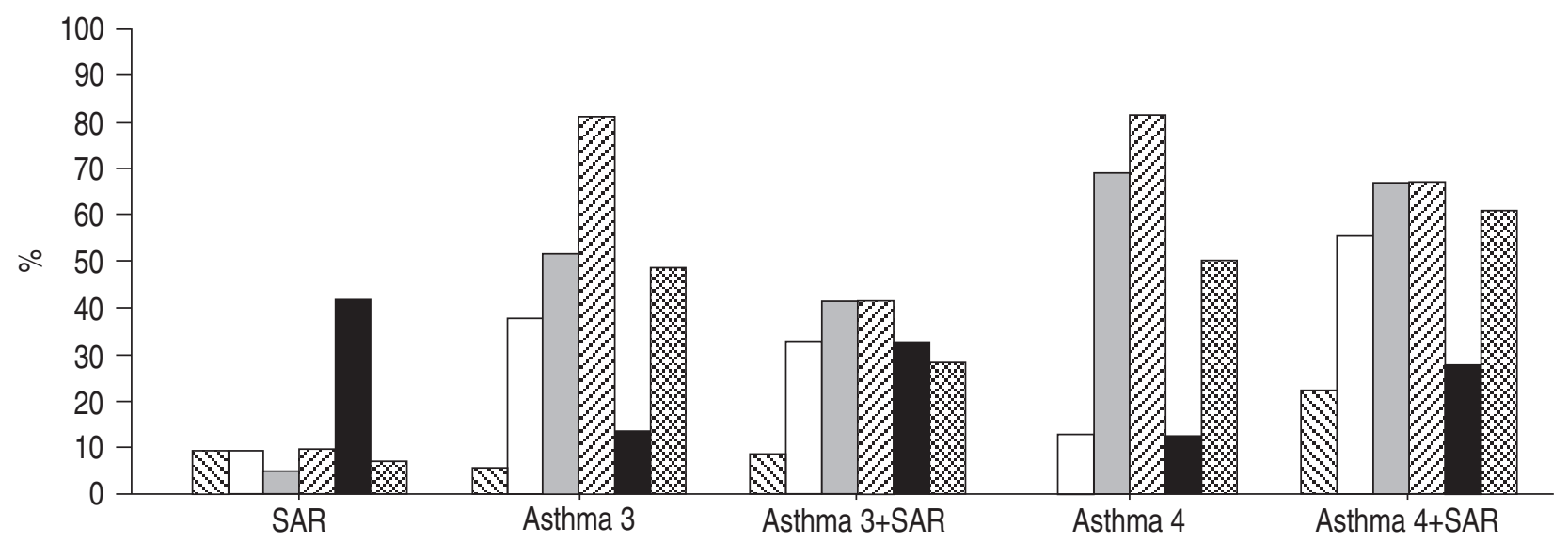

Fig. 1.- Pharmacotherapy use $(\%)$ in children and adolescents (aged 6-17 yrs). $\mathbb{\$}$ : intranasal agents; $\square$ : disodium cromoglycate, nedocromil sodium (inhaled); : corticosteroids (inhaled); $\mathbb{Z}$ : sympathomimetics (inhaled); $\mathbf{\square}$ : antihistamines (oral); $\mathbf{a}$ : others (oral sympathomimetics, corticosteroids, theophylline, leukotriene antagonists, anticholinergic agents). SAR: seasonal allergic rhinitis; Asthma 3: moderate asthma; Asthma 4: severe asthma.

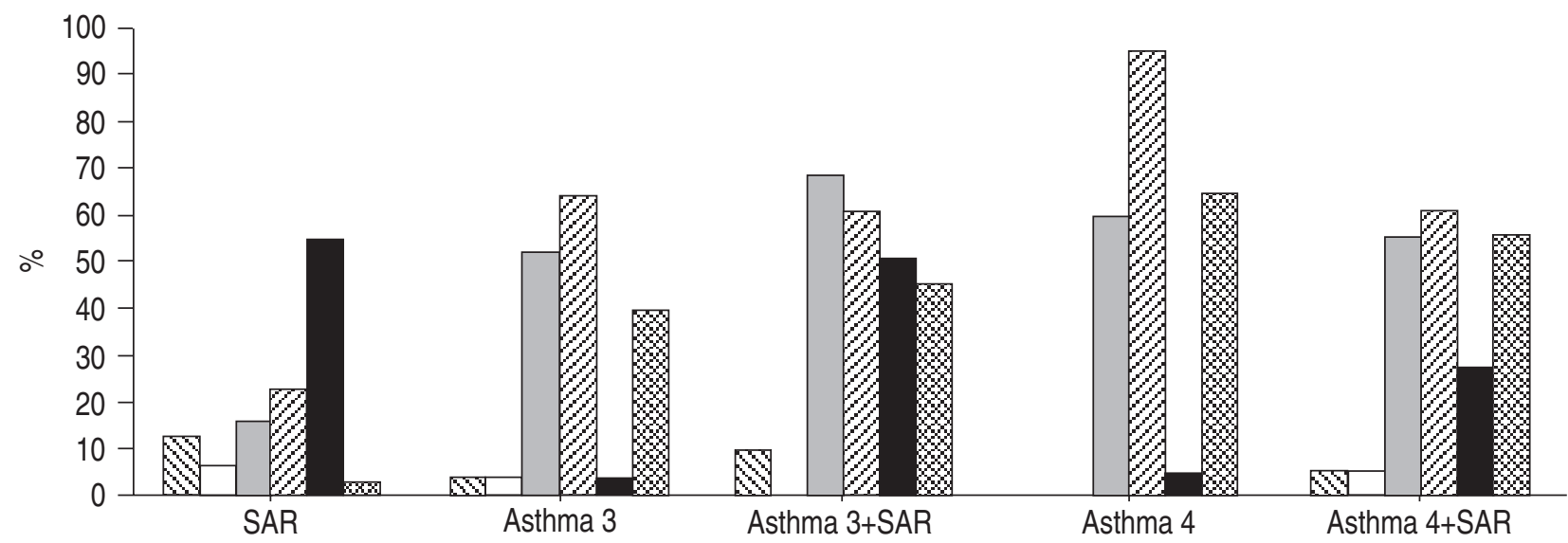

Fig. 2.- Pharmacotherapy use (\%) in adults (aged 18-70 yrs). $\mathbb{\$}$ : intranasal agents; $\square$ : disodium cromoglycate, nedocromil sodium (inhaled); : corticosteroids (inhaled); $\mathbb{Z}$ : sympathomimetics (inhaled); $\mathbf{\square}$ : antihistamines (oral); $\mathbf{a}$ : others (oral sympathomimetics, corticosteroids, theophylline, leukotriene antagonists, anticholinergic agents). SAR: seasonal allergic rhinitis; Asthma 3: moderate asthma; Asthma 4: severe asthma.

beclometasone dipropionate or disodium cromoglycate) and inhaled disodium cromoglycate/nedocromil. Use of prescribed inhaled sympathomimetics and corticosteroids increased proportionately to illness severity.

Comparing asthma patients with those also suffering from SAR revealed that inhaled sympathomimetics were used by $81 \%$ of children/adolescents with severe asthma but only by $67 \%$ with severe asthma and SAR, whereas inhaled sympathomimetics were used by $95 \%$ and $61 \%$ of adults, respectively.

ICS therapy was used more by children/adolescents with asthma (69\% of patients with severe asthma) than by children with SAR $(5 \%)$. ICS use by adults ranged between $69 \%$ (moderate asthma and SAR) and $16 \%$ (SAR).

OTC medications were used by $15 \%(n=41)$ of children/adolescents and $26 \%(n=57)$ of adults. In both groups, patients with SAR or both asthma and SAR required OTC medication twice as often as patients who only had asthma.

\section{Annual direct medical and nonmedical costs}

Figure 3 shows annual direct and indirect costs. Annual direct costs for TPPs ranged from $€ 569$ per adult with SAR to $€ 2,048$ per adult with severe asthma and SAR. Cost drivers of direct medical costs for children/adolescents were rehabilitation $(36 \%)$ followed by drug costs $(24 \%)$, whereas for adults, drug costs predominated $(52 \%)$ followed by medical services $(23 \%)$.

The financial burden on patients ranged from $€ 122$ (adults with moderate asthma) to $€ 1,889$ (children/ adolescents with severe asthma and SAR) and was principally due to household modifications (e.g. replacing carpets with washable floors), the purchase of beddings (for patients sensitised to house dust mites) or special vacuum cleaners. The average cost of the above for children/adolescents was $€ 535$, followed by the cost of additional therapies (e.g. acupuncture, physiotherapy, biofeedback; $€ 11)$ and OTC medication 


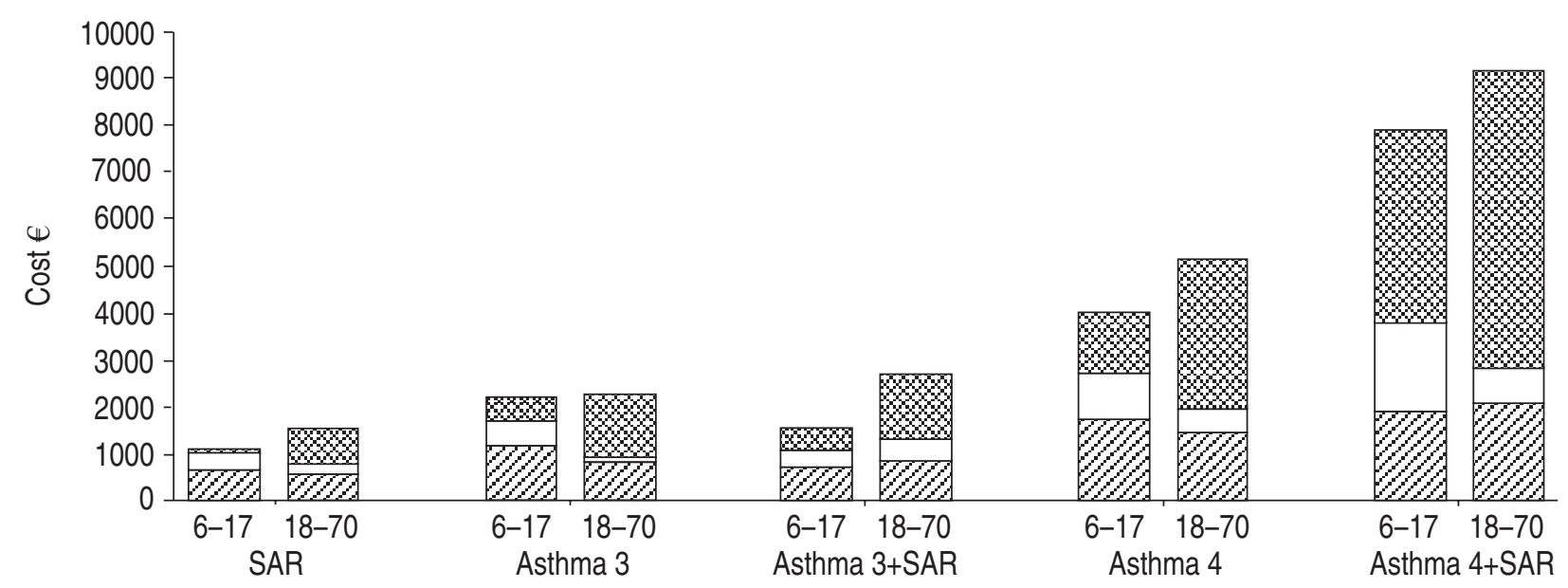

Fig. 3.-Total annual cost per patient with atopic asthma and seasonal allergic rhinitis (SAR) in Germany. $\mathbb{Z}$ : direct costs, third-party payers; $\square$ : direct costs, patient; $\mathbf{F}$ : indirect costs. Asthma 3: moderate asthma; Asthma 4: severe asthma.

(€9). Expenses for adults averaged $€ 244$ for household modifications, $€ 40$ for additional therapies and $€ 32$ for medication co-payment. Adults paid $12 \%$ of their total costs privately, whereas $26 \%$ of the total costs for children/adolescents were paid privately.

\section{Total costs}

Overall, total annual costs per patient (including direct as well as indirect costs) rose as asthma severity increased and if asthma was combined with SAR (fig. 3). The total average cost for children/adolescents with SAR was $€ 1,089$ ( $€ 1,543$ for adults). Total costs rose to $€ 2,202$ per child/adolescent with moderate asthma and $€ 2,745$ per adult, and rose further to $€ 7,928$ per child/adolescent with severe asthma plus SAR and to $€ 9,286$ per adult. Comparison of direct and indirect costs revealed that the latter were a major component of total costs: $6 \%$ of total costs for children/adolescents with SAR and as much as $69 \%$ for adults with severe asthma and SAR. The principal indirect cost was lost productivity due to occupational disability and premature retirement of patients and caregivers (adults, 83\%; children/adolescents, 76\%). The portion of lost productivity due to absence from work was $17 \%$ in adults and $24 \%$ in children and adolescents.

\section{Discussion}

This study assessed the average cost of atopic asthma and SAR per patient in Germany and compared illness severity to costs. The findings show an enormous increase in total costs as asthma severity increases and when combined with SAR. On average, the total annual cost was $€ 1,089$ for children/ adolescents with SAR and $€ 1,543$ for adults. Annual costs for children/adolescents with severe asthma plus SAR increased to $€ 7,928$ per patient and to $€ 9,286$ for adults.

The calculated atopic asthma costs are in line with published European cost-of-illness studies. Variations in total average cost per patient between these economic studies are partly due to differences between inclusion/exclusion criteria, cost assessment, treatments and healthcare systems. The financial burden of allergic asthma and/or SAR from the TPPs perspective is further comparable to other chronic diseases, such as diabetes mellitus type 2, in Germany [20, 21].

Schulenburg et al. [10] collected data from 216 German patients. The total average cost per patient per year was $€ 2,689$ for an adult with moderate asthma and $€ 6,144$ for an adult with severe asthma. The annual direct medical cost for children was $€ 1,649$ for moderate asthma and $€ 2,460$ for severe asthma. The disregard of nonmedical expenditures may have affected these findings. SchulenBurg et al. [10] described how asthma-related costs more than doubled as severity increased, a finding confirmed by Serra-Batlles et al. [22] and Godard et al. [23].

The present authors identified rehabilitation, inpatient care (particularly for children) and indirect costs as the main cost factors for patients with severe asthma. The average hospital stay for all patients was 12.1 days, which is in line with official German data [19].

The occupational disability and premature retirement of asthma patients and caregivers account for the largest proportion of indirect costs. SCHULENBURG et al. [10] show hospitalisation and indirect costs to increase disproportionately to increases in illness severity. Since the costs of patients with severe asthma are high, overall expenditure could be reduced by preventive medical treatment, which slows progression of the illness.

A Spanish study included 333 patients, aged $\geqslant 14$ yrs [22]. The average annual asthma-related costs were estimated to be $€ 3,251$ per patient (ranging from $€ 2,718$ for moderate asthma to $€ 7,219$ for severe asthma). A prospective French study conducted over $1 \mathrm{yr}$ calculated direct costs per patient (excluding hospitalisation) to be between $€ 1,196$ (moderate asthma) and $€ 2,782$ (severe asthma) [23].

A 1996-1997 cost of illness study of 589 Swiss 
patients calculated the following total annual asthma costs: $€ 558$ per child, $€ 2,064$ per adult and $€ 1,766$ overall. An asthma attack increased the overall annual cost to $€ 2,869$ [24]. In contrast, the average cost of $€ 609$ per British patient suffering from an asthma attack (Hoskins et al. [25]) seems comparatively small, but indirect costs, personal expenses and direct nonmedical costs were not included. This study also demonstrated that poorly controlled asthma has considerable impact on healthcare costs; the average cost for a patient with an attack was $>3.5$ times that for a patient without one.

Use of prescribed inhaled sympathomimetics and corticosteroids increased with severity of illness. ICS and inhaled sympathomimetics were used more frequently by children/adolescents with only asthma than by those with concomitant SAR, suggesting that the former is more serious. However, intranasal agents and antihistamines are used more frequently by patients with concomitant SAR suggesting that allergic symptoms predominate in these patients. Asthma guidelines [14, 26] recommend ICS as standard therapy for moderate and severe asthma, yet only $56-60 \%$ of severe (adult) asthmatics were treated with ICS by their pulmonologist. However, the frequency of ICS use may be underestimated since, on average, adults had four further appointments per year with other doctors (e.g. general practitioners). Paediatricians prescribed ICS for $46-68 \%$ of children/ adolescents. This also indicates that ICS is underutilised. On average, children/adolescents had two further appointments per year with other doctors. A recent German report also indicated that pharmacotherapy for bronchial asthma is underused or inadequate. In particular, treatment with inhaled corticosteroids is insufficient, whereas short-term sympathomimetics are excessively prescribed. Only one-third of asthma patients were treated according to asthma guidelines [27].

Possible limitations of the study presented here include retrospective documentation of patients' expenses, which introduces a potential recall bias. Personal expenses of German asthma patients have not been previously published. The data are a starting point for further research. A selection bias favouring doctors interested in asthma/SAR care may also be present and a further selection bias may be introduced because study subjects were recruited by these doctors. Since illness severity was classified by these doctors, according to GINA recommendations, no physical examination was required. The use of the human capital approach is the traditional method of calculating indirect costs in the form of overall production losses. This is morally questionable, since it discriminates against unemployed persons, pensioners and housewives because they have no market value. However, the human capital approach assesses the abilities and knowledge of an individual or group that can be used in the production process. This study makes no claim to be representative of Germany as a whole.

In summary, the high average annual costs per patient, especially for the treatment of severe asthma, indicate poor control of asthma, especially in terms of medications. This is also reflected by the high indirect costs of early retirement and occupational disability in severe asthma. In line with previous studies, these results strongly suggest that costs may be significantly reduced by improved illness control. Investment in asthma education programmes and innovative pharmacotherapies that treat the aetiology and slow progression of the illness may reduce costs.

Acknowledgements. The authors are obliged to patients and parents who consented to take part in this study and the helpful cooperation of physicians and practice assistants without whom this study would not have been feasible.

\section{References}

1. von Mutius E. The rising trends in asthma and allergic disease. Clin Exp Allergy 1998; 28: Suppl. 5, 45-49.

2. de Weck A. Allergies, an increasing public health problem: causes and consequences. Allergy Immunol 2000; 32: 6-11.

3. Burney P, Chinn S, Jarvis D, Luczynska C, Lai E and on behalf of the European Community Respiratory Health Survey. Variations in the prevalence of respiratory symptoms, self-reported asthma attacks, and use of asthma medication in the European Community Respiratory Health Survey (ECRHS). Eur Respir J 1996; 9: 687-695.

4. The International Study of Asthma and Allergies in Childhood (ISAAC) Steering Committee. Worldwide variation in prevalences of symptoms of asthma, allergic rhinoconjunctivitis, and atopic eczema: ISAAC. Lancet 1998; 351: 1225-1232.

5. Slavin RG. Sinopulmonary relationships. Am J Otolaryngol 1994; 15: 18-25.

6. Linna O, Kokkonen J, Lukin M. A 10-year prognosis for childhood allergic rhinitis. Acta Paediatr 1992; 81: $100-102$.

7. Nowak D, Volmer T, Wettengel R. Asthma - eine Krankheitskostenanalyse. [Bronchial asthma - an economic evaluation]. Pneumologie 1996; 50: 364-371.

8. Weissflog D, Matthys H, Virchow JC Jr. Epidemiology and costs of bronchial asthma and chronic bronchitis in Germany. Dtsch Med Wochenschr 2001; 126: 803-808.

9. Wettengel R, Volmer T. Ökonomische Aspekte. In: Wettengel R, Volmer T, eds. Asthma - Medizinische und Ökonomische Bedeutung einer Volkskrankheit. [Asthma - Medical and economic relevance of a public disease]. Stuttgart, Norbert Rupp, 1994; pp. 35-68.

10. Schulenburg JM, Greiner W, Molitor S, Kielhorn A. Kosten der Asthmatherapie nach Schweregrad. Eine empirische Untersuchung. [Costs of asthma therapy according to level of severity]. Med Klin 1996; 91: 670 676.

11. Welsh PW, Stricker WE, Chu CP, et al. Efficacy of beclomethasone nasal solution, flunisolide, and cromolyn in relieving symptoms of ragweed allergy. Mayo Clin Proc 1987; 62: 125-134.

12. Pipkorn U, Proud D, Lichtenstein LM, KageySobotka A, Norman PS, Naclerio RM. Inhibition of mediator release in allergic rhinitis by pretreatment with topical glucocorticosteroids. N Engl J Med 1987; 316: $1506-1510$.

13. Thefeld W, Bergmann K, Hermann-Kunz E. 
Wohnortgröße und Gesundheit: Stadt-/Landunterschiede. [Place of domicile and health: Differences between urban and rural areas]. In: Bellach B-M, ed. Die Gesundheit der Deutschen. [Health in Germany]. Bd. 2, Heft 15, 1996; pp. 1-15.

14. National Heart Lung and Blood Institute. Global Initiative for Asthma. Global strategy for asthma management and prevention. NHLBI/WHO workshop report. Publication no. 95-3659. Bethesda, National Institutes of Health, 1995.

15. Mundenbruch R. Einheitliche Bewertungsmaßstab (EBM): Bewertungsmaßstab für kassenärztliche Leistungen (BMÄ) und Ersatzkassen-Gebührenordnung (E-GO). [German tariff list for medical services (EBM). October 2000. Federal Association of Public Health Insurers (KBV)]. 31st edn. Germany, Zauner Verlag, 2000.

16. Rote Liste 2000. Arzneimittelverzeichnis für Deutschland (einschliesslich EU-Zulassungen und bestimmter Medizinprodukte. [Tariff list for drugs in Germany (including EU-admissions and special medical products)]. Frankfurt, Red List Service GmbH; 2000.

17. Anonymous. Zahlenbericht 1999/2000. Verband der Privaten Krankenversicherung. [Report 1999/2000. Association of private health insurance]. Köln, Verband der Privaten Krankenversicherung, 2000.

18. Ungar WJ, Peter CC and and the Pharmacy Medication Monitoring Program Advisory Board. Measuring productivity loss days in asthma patients. Health Econ 2000; 9: 37-46.

19. Federal Statistical Office. Statistisches Jahrbuch 2000 für die Bundesrepublik Deutschland. [Statistical Yearbook 2000 for the Federal Republic of Germany]. Wiesbaden, Metzler-Poeschel, 2000.
20. Liebl A, Neiss A, Spannheimer A, et al. Complications, co-morbidity, and blood glucose control in type 2 diabetes mellitus patients in Germany - results from the CODE-2TM study. Exp Clin Endocrinol Diabetes 2002; 110: 10-16.

21. Palmer AJ, Brandt A, Gozzoli V, Weiss C, Stock H, Wenzel $\mathrm{H}$. Outline of a diabetes disease management model: principles and applications. Diabetes Res Clin Pract 2000; 50: Suppl. 3, 47-56.

22. Serra-Batlles J, Plaza V, Morejón E, Comella A, Brugues J. Costs of asthma according to the degree of severity. Eur Respir J 1998; 12: 1322-1326.

23. Godard P, Chanez P, Siraudin L, Nicoloyannis N, Duru G. Costs of asthma are correlated with severity: a 1-yr prospective study. Eur Respir J 2002; 19: 61-67.

24. Szucs TD, Anderhub H, Rutishauser M. The economic burden of asthma: direct and indirect costs in Switzerland. Eur Respir J 1999; 13: 281-286.

25. Hoskins G, McCowan C, Neville RG, Thomas GE, Smith B, Silverman S. Risk factors and costs associated with an asthma attack. Thorax 2000; 55: 19-24.

26. Wettengel R, Berdel D, Hofmann D, et al. Asthmatherapie bei Kindern und Erwachsenen. Empfehlungen der Deutschen Atemwegsliga. [Asthma therapy in children and adults. Recommendations of the German Respiratory League]. Med Klin 1998; 93: 639-650.

27. Sachverständigenrat für die konzertierte Aktion im Gesundheitswesen. Bedarfsgerechtigkeit und Wirtschaftlichkeit, Band III. Über- Unter- und Fehlversorgung. [Advisory Council for the Concerted Action in Healthcare. Appropriateness and efficiency, Volume III. Over-, under- and misuse]. Report 2000/2001. Baden Baden, Nomos Verlagsgesellschaft, 2002. 